\title{
Kinetic Parameters Estimation for Ascorbic Acid Degradation in Fruit Nectar Using the Partial Equivalent I sothermal Exposures (PEIE) Method under Non-Isothermal Continuous Heating Conditions
}

\author{
Margarida C. Vieira, ${ }^{\dagger}$ Arthur A. Teixeira, ${ }^{\ddagger}$ and Cristina L. M. Silva* \\ Escola Superior de Biotecnologia, Univ. Católica Portuguesa, Rua Dr. António Bernardino de Almeida, \\ 4200-072 Porto, Portugal
}

\begin{abstract}
With the purpose of testing the Paired Equivalent Isothermal Exposures (PEIE) method to determine reaction kinetic parameters under non-isothermal conditions, continuous pasteurizations were carried out with a tropical fruit nectar [ $25 \%$ cupuaçu (Theobroma grandiflorum) pulp and $15 \%$ sugar] to estimate the ascorbic acid thermal degradation kinetic parameters. Fifteen continuous thermal exposures were studied, with seven being cycled. The experimental ascorbic acid thermal degradation kinetic parameters were estimated by the PEIE method $\left(\mathrm{E}_{\mathrm{a}}=73 \pm 9 \mathrm{~kJ} / \mathrm{mol}, \mathrm{k}_{80^{\circ} \mathrm{C}}=0.017 \pm\right.$ $\left.0.001 \mathrm{~min}^{-1}\right)$. These values compared very well to the previously determined values for the same product under isothermal conditions $\left(E_{a}=73 \pm 7 \mathrm{~kJ} / \mathrm{mol}, \mathrm{k}_{80^{\circ} \mathrm{C}}=0.020\right.$ $\left.\pm 0.001 \mathrm{~min}^{-1}\right)$. The predicted extents of reaction presented a good fit to the experimental data, although the cycled thermal treatments presented some deviation. In addition to being easier and faster than the I sothermal method, the PEIE method can bea more reliable method to estimate first-order reaction kinetic parameters when continuous heating is considered.
\end{abstract}

\section{Introduction}

To date the design of food thermal processes has assumed conservative safety factors, which, although reliable, result in overprocessing that adversely affects food quality. Therefore, reduction of microbial loads to a safe level (pasteurization or commercial sterilization), while avoiding major changes in the product's quality attributes, became one of the most important fields in food research. Knowledge of thermal kinetic parameters of quality and safety attributes along with a reaction model in a food product allows prediction of concentration retention or microbial survivors for a given thermal process. Therefore, optimal thermal processing conditions can be obtained by minimizing the microbial load and maximizing the retention of quality attributes in a food product.

A thermal process comprises three periods: a heating period, a holding period, and a cool ing period. To evaluate a thermal process, the time temperature profile has to be known for the slowest heating particle (1), which is easier to obtain if the product is in a regular shaped container (e.g., a can or a retortable pouch), but not so easy when dealing with continuous flow. Depending on the rheological properties of the fluid, e.g., in laminar flow, a pronounced velocity profile might occur. The slowest heating particles will then bethe fastest particles travelling along the longitudinal axis of the holding tube.

\footnotetext{
* Corresponding author. Tel: 351-22-5580058. Fax: 351-225090351. Email: crislui@esb.ucp.pt.

† Escola Sup. de Tecnologia, Universidade do Algarve,Campus da Penha, 8000 Faro, Portugal. E-mail: mvieira@ualg.pt.

₹ Agricultural and Biological Engineering Department, University of Florida, P.O. Box 110570, Gainsville, FL 32611-0570.
}

Safe holding tube design in such a system necessarily leads to overprocessing of all of the other particles. Especially for low viscosity fluids the flow regime should be turbulent once it approaches plug flow (1). In continuous systems, the relevance of the heating and cooling periods to the extent of any reaction depends on various factors: rheol ogic behavior of the food product, flow rate, temperature of the thermal process, equipment used, and reaction rate. Except for slow rates of reaction or conditions that lead to very short heating and cooling periods when compared to the holding period, using the isothermal approach to estimate kinetic parameters gives results that can be reliable only to a certain extent (2). However, the isothermal approach, although not realistic, is useful when there is a need to determine reaction models (3).

A dynamic approach $(2,4,5)$ has been proposed as a better tool to evaluate kinetic parameters, once it can use the actual industrial equipment, taking into account the whole non-isothermal heating exposure (even in the holding tube there is heat loss al ong the tube) and can be applied to uniform (plug flow) or non-uniform heating fluids (6).

Equivalent Point Method (EPM). The equivalent point method (EPM) (5) is a non-isothermal method that considers a dynamic heating process as an equivalent isothermal process. This method was claimed to be independent of the activation energy $\left(E_{a}\right)$ value. A new reference time concept was introduced, the "G value" (eq $1)$, similar to the $F_{0}$ value but restricted to use when the

$$
\mathrm{G}=\int_{0}^{\mathrm{t}} \exp \left(-\frac{\mathrm{E}_{\mathrm{a}}}{\mathrm{RT}}\right) \mathrm{dt}
$$


kinetic characteristics of the quality attribute are known. The $G$ value can also be defined by eq 2 for an equivalent

$$
G=t_{E} \exp \left(-\frac{E_{a}}{R T_{E}}\right)
$$

thermal exposure. On the basis of the fact that, for firstorder reactions and for a given $E_{a}$, any change in concentration of a quality attribute could be defined by a straight line representing all possible combinations of time-temperature that would cause that change, this method postulated that varying $\mathrm{E}_{\mathrm{a}}$ would produce an infinite number of straight lines, all intersecting in one point, the equivalent point (EP) with coordinates $\left(t_{E}, T_{E}\right)$. However, there were cases where not all lines would intersect at the same point. Swartzel (5) considered the cause to be the inherent experimental and calculation errors. Different numerical methods were later tried (7), but only with nonlinear least square regression (NLSR) or weighted least squares linear regression (WLSR) were good results obtained. The greatest accuracy was reached throughout the range of $E_{a}$ values with the WLSR method, the simpler method to be used. As computational problems would arise from the fact that most microcomputers have a limit for the argument of the exponential function (-96.9) so that $E_{a} \leq 300 \mathrm{~kJ} / \mathrm{mol}$ (8), a finite reference temperature was introduced in the method ( 7 , 9):

$$
\mathrm{G}_{\mathrm{T}_{\text {ref }}}=\int_{0}^{\mathrm{t}} \exp \left[\left(-\frac{\mathrm{E}_{\mathrm{a}}}{\mathrm{R}}\right)\left(\frac{1}{\mathrm{~T}(\mathrm{t})}-\frac{1}{\mathrm{~T}_{\text {ref }}}\right)\right] \mathrm{dt}
$$

Validation of the EP method was al ready attempted several times for non-isothermal heat processes (10-13). Maesmans et al. (12) concluded that when the heating pattern deviated from isothermal conditions the degradation kinetics of a quality parameter, estimated by this method, would start differing from the calculated values using the temperature profile.

Paired Equivalent Isothermal Exposures (PEIE) Method. Recently, another method was developed to help overcome the imperfect intersections of some thermal curves when the EPM was applied. The paired equivalent isothermal exposures (PEIE) (6) estimates thermal kinetic parameters of reactants in nonuniform heating processes. This method, as the EP method, can also be a faster and more economic and realistic way of estimating kinetic parameters of thermal degradation. It differs from the EP method by being iterative and estimates kinetic parameters from at least one pair of dynamic thermal treatments (6) with corresponding extents of reaction. Two $E_{a}$ values rel ated $\left(E_{a 2}=2 \times E_{a 1}\right.$; or any other relationship that ensures a significant difference between the two values) are initially assumed. The $G_{1}$ and $G_{2}$ values are then calculated (eq 1), and two straight lines are obtained:

$$
\begin{aligned}
& \ln t_{E}=\ln G_{2}+\frac{E_{a 1}}{R T_{E}} \\
& \ln t_{E}=\ln G_{1}+\frac{E_{a 2}}{R T_{E}}
\end{aligned}
$$

The point of intersection of the two lines is now defined as an equival ent isothermal exposure (EIE) (6), although the coordinates are the same as those of the EP method $\left(t_{E}, T_{E}\right) . T_{E}$ and $t_{E}$ are obtained by solving eqs $4 a$ and $4 b$ simultaneously. Next, the corresponding isothermal rate constants, $\mathrm{k}_{\mathrm{E}}$ 's are determined for each thermal exposure:

$$
k_{E}=-\frac{\ln \left(C / C_{0}\right)_{\exp }}{t_{E}}
$$

From an Arrhenius plot of In $\mathrm{K}_{\mathrm{E}}$ vs $1 / \mathrm{T}_{\mathrm{E}}$ a new $\mathrm{E}_{\mathrm{a} 1}$ and $\mathrm{k}_{\text {ref }}$ are obtained (dynamic set), and the second iteration starts with the generation of a new $E_{\mathrm{a} 2}$ by doubling the new $E_{a 1}$. This iterative procedure continues until there is no difference between the dynamic sets obtained in two consecutive iterations.

For $n$ thermal exposures, $n(n-1) / 2$ pairs can be obtained along with corresponding In $k_{E n}$ and $1 / T_{E n}$ values. The Arrenhius plot will next give the dynamic set $\left(E_{a}\right.$ and $\left.k_{r e f}\right)$ for the equivalent isothermal exposure.

Line Intersection (LI) Procedure. Very recently, to overcome the intersection problem of the EPM, another procedure was introduced by Kyereme et al. (15), the new line intersection ( $\mathrm{LI}$ ) procedure. This method determines, in a very accurate manner, $F_{0}$ and thermal impact on quality change using the original EPM. However, to generate kinetic data during continuous flow an iterative procedure has also to be applied, which is in essence similar to the PEIE method. In this method, a "characteristic curve" is generated by plotting In t versus $T$ for selected $E_{a}$ values. All In t versus $T$ lines will form tangents to a new curve referred to as the "characteristic curve". By choosing two different initial thermal treatments (thermal curves), two different thermal "characteristic curves" are generated. If a set of ( $t, T)$ values are selected in one curve, the slope of the line tangent to that curve passing through that point is $\mathrm{E}_{\mathrm{a}}$. This slope is then used to locate in the second curve another set $(t, T)$. From the two pairs of $(t, T)$ two $k$ values are determined using eq 5, and then, through an Arrhenius plot, $E_{a}$ and $k_{\text {ref }}$ are estimated. The kinetic data is then tested using the results with both sets of $t$ and $T$, and the retention values, $\mathrm{C} / \mathrm{C}_{0}$, and the process becomes iterative until values are in agreement.

Validation of the PEIE Method. The PEIE method was theoretically validated with three different sets of non-isothermal processes data (6) with experimental uncertainty simulated in the final concentration data. The method was also validated for conduction heating foods under nonuniform heating (pea puree in cans inoculated with Bacillus stearothermophilus spores) (14). Fourteen experiments were used, which would give in theory 91 experimental pairs. However, it was reported that only thermal exposures that yielded significantly different equivalent temperatures could be used, and therefore, only some pairs were allowed, which accounted for 34 data points. The method has not been validated yet for continuous non-isothermal processes.

In a previous study (16), the kinetic parameters of thermal degradation of ascorbic and dehydroascorbic acid in a cupuaçu (Theobroma grandiflorum) nectar ( $25 \%$ pulp and $15 \%$ sugar) were determined in the pasteurization temperature range $\left(60-100{ }^{\circ} \mathrm{C}\right)$ using the isothermal method (steady state) (17). The time range studied was up to $240 \mathrm{~min}$. A mathematical model was obtained for each form of vitamin C. For ascorbic acid, the reversible first-order model presented the best fit to the experimental data. However, considering the time range applied to pasteurization processes in industry (from a few seconds in continuous processes to $30 \mathrm{~min}$ in batch processes) (18), the first-order model presented a very good fit to the experimental data up to 30 min (Table 1). For dehydroascorbic acid, a mechanistic model was 
Table 1. Kinetic Parameters of Thermal Degradation of Ascorbic Acid (AA) in Cupuaçu Nectar Using the I sothermal Method (18 ${ }^{\circ}$ Brix, pH 3.2 ) (16)

\begin{tabular}{|c|c|c|c|c|}
\hline fitted model & $\begin{array}{c}E_{a} \\
(k J / m o l)\end{array}$ & $\mathrm{k}_{80^{\circ} \mathrm{C}}\left(\mathrm{min}^{-1}\right)$ & $\mathrm{C}_{\mathrm{AA}}$. & $\mathrm{R}^{2}$ \\
\hline $\begin{array}{l}\left(C_{A A}-C_{A A_{\infty}}\right) /\left(C_{A A_{0}}-C_{A A_{\infty}}\right)=e^{-k t} \\
C_{A A} / C_{A A_{0}}=e^{-k t}\end{array}$ & $\begin{array}{l}74 \pm 5 \\
73 \pm 7\end{array}$ & $\begin{array}{l}0.032 \pm 0.003 \\
0.020 \pm 0.001\end{array}$ & $\begin{array}{l}0.32 \\
0.00\end{array}$ & $\begin{array}{l}0.994 \\
0.996\end{array}$ \\
\hline
\end{tabular}

obtained, and because of its complexity, this form of vitamin C was not used to compare the PEIE method with the isothermal method.

The objective of this study was to compare the PEIE method to the isothermal method in estimating the thermal degradation reaction kinetic parameters of a qual ity attribute (ascorbic acid) on a fluid food with low $\mathrm{pH}(\cong 3.2)$, cupuaçu nectar, under continuous thermal heating in the pasteurization temperature range.

\section{Materials and Methods}

Cupuaçu Nectar Preparation. Cupuaçu pulp was imported frozen from Belém, Brazil, and stored at -20 $\pm 2{ }^{\circ} \mathrm{C}$. Right before the experiments, it was taken out of the freezer and cut into small chunks. Refined sugar plus dei onized water were then added to the pulp in order to obtain a nectar with $25 \%$ pulp and $15 \%$ sugar. The mixture was homogenized with a Moulinex Turbomix 2 blender during $5 \mathrm{~min}$ and passed through a plastic screen; ${ }^{\circ} \mathrm{Brix}$ and $\mathrm{pH}$ were measured with an Atago hand refractometer and a Crison micropH meter 2001, respectively.

Continuous System Setup. The tests were conducted under nonuniform heating conditions. A plate heat exchanger and a holding tube have been used (Armfield pasteurizer FT-43A). To produce different $t_{E}$ and $T_{E}$, different processing temperatures and flow rates were used. The pasteurizer had 32 plates in the heating section $(8 \mathrm{~cm} \times 12 \mathrm{~cm})$, with an available surface area of $57 \mathrm{~cm}^{2}$. The holding tube (stainless steel, id $=1 \mathrm{~cm}$ ) was composed of four sections, the last two being immersed in a water bath set at the temperature needed, to avoid a great temperature drop due to heat losses. Depending on the thermal exposure needed, the length of the holding tube was increased or decreased by adding or subtracting sections, ranging from 4.5 to $21 \mathrm{~m}$.

Time-Temperature History. To obtain the timetemperature history, an el ement of volume dv was dyed with a $2 \%(\mathrm{w} / \mathrm{v})$ solution of M ethylene Blue, by injecting $1 \mathrm{~mL}$ at the entrance of the feeding tube at time $0 \mathrm{~min}$. The temperature changes in dv were monitored along the pathway by inserting TCT thermocouples between the pasteurizer plates, on the product side, and at the entrance and exit of each hol ding tube section and cooling tube. The temperature data were recorded by a data acquisition system (Delta Logger devices). The corresponding traveling time of $d v$ (from the entrance to each site of insertion of a thermocouple) was recorded using a stopwatch and visual detection of the blue-dyed nectar (Figure 1).

Thermal Treatments. Fifteen different thermal exposures were applied to cupuaçu nectar.

In eight thermal exposures, heating cycles were applied (Figure $2 \mathrm{~b}$ and $\mathrm{c}$ ), e.g., two cycles were produced by feeding $2 \mathrm{~L}$ of nectar to the continuous system to be thermally processed once (first cycle). The whole volume was then collected at the exit in a refrigerated vessel for $0.5 \mathrm{~h}$. A sample was taken for ascorbic acid analysis and the nectar was put back in the feeding tank to be exposed to a second thermal process (second cycle). Meanwhile,

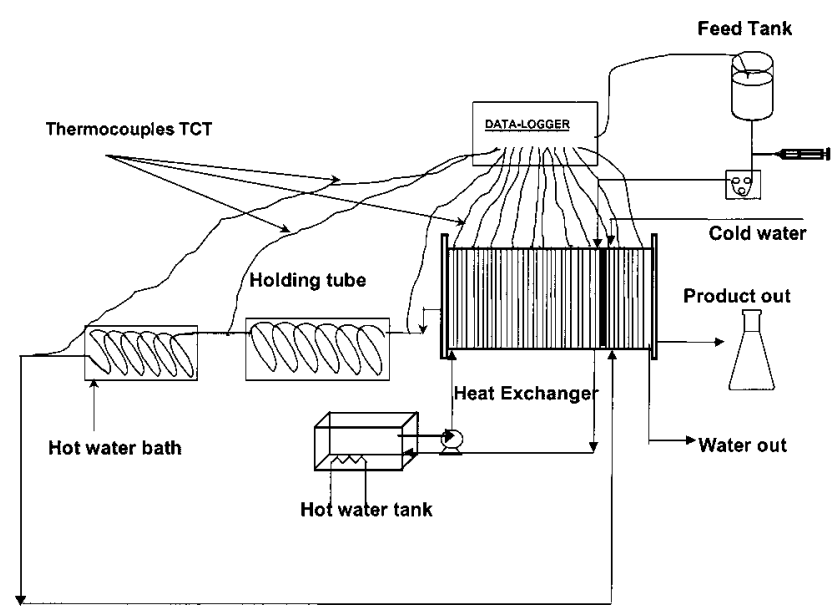

Figure 1. Continuous system setup.

a)

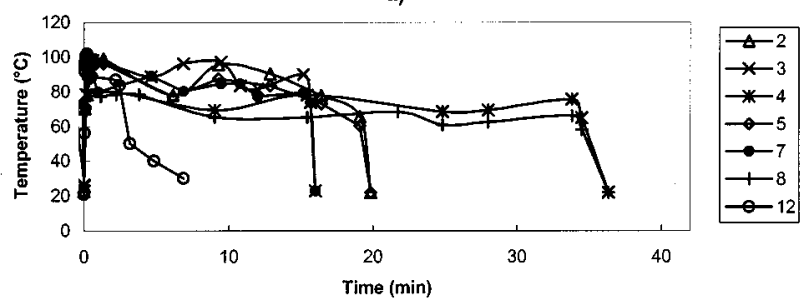

b)

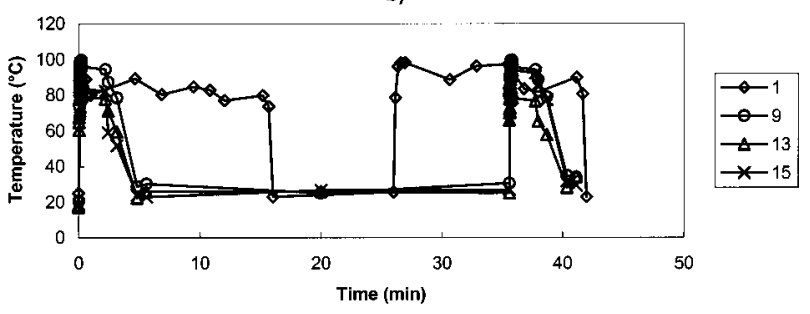

c)

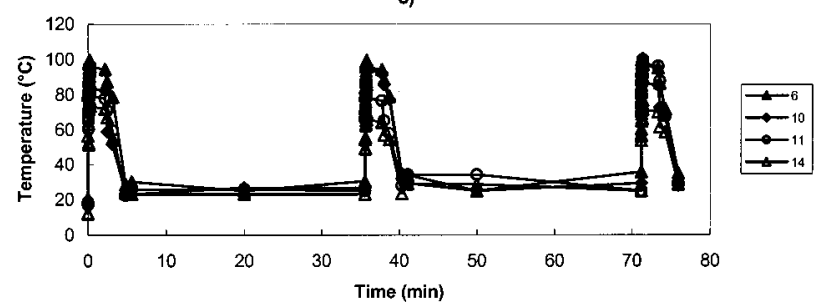

Figure 2. Time-temperature histories for all 15 runs: (a) single thermal treatments, (b) two cycles thermal treatments, (c) three cycles thermal treatments.

the system was cleaned with water. In these experiments only two sections of holding tube were used.

Ascorbic Acid Analysis. For each experiment ascorbic acid and dehydroascorbic acid content were determined experimentally by HPLC UV detection using isoascorbic acid (IAA) (Fluka) as internal standard (16).

Residence Time Distribution (RTD) Study. As some dispersion was visually detected on the transparent tubing when Methylene Blue was used as tracer, as described above, a study on residence time distribution (RTD) was carried out to verify if the time-temperature histories needed to be corrected. Once the spectrophotometry method could not detect low concentrations of Methylene Blue in such a thick medium as cupuaçu nectar, another tracer $(5 \%$ of $\mathrm{NaCl})$ and detection method (electrical conductimetry, Crison conductimeter) were used. A calibration curve was first done with different 

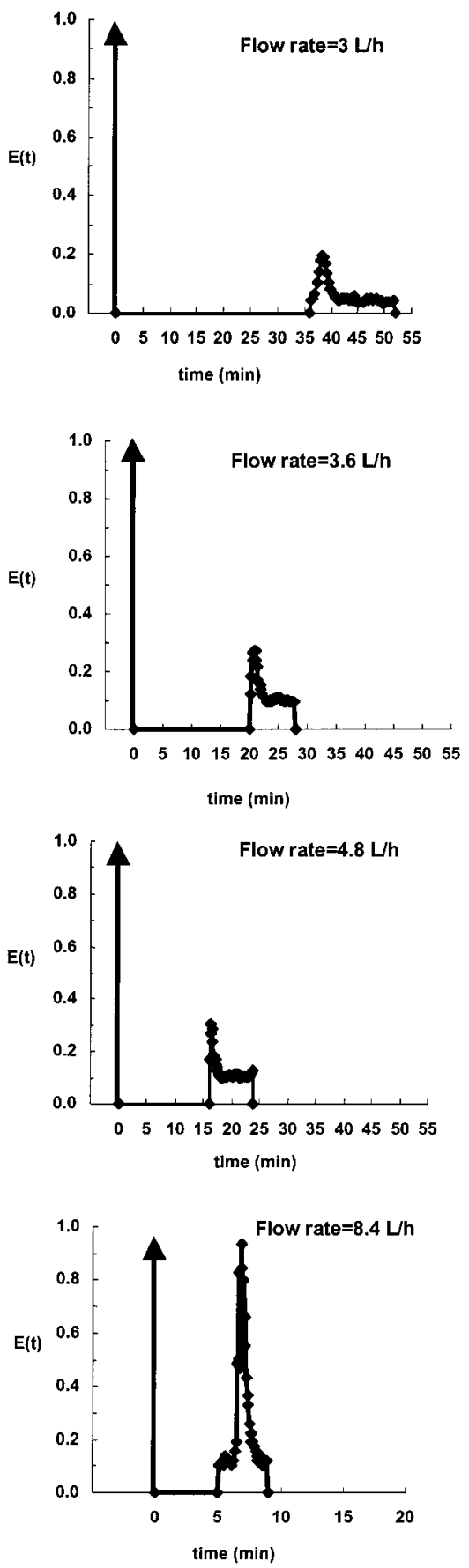

Figure 3. Residence time distribution (RTD) of cupuaçu nectar flowing through the system and detected at the exit of the system (the arrow represents tracer injection).

concentrations of $\mathrm{NaCl}$ in cupuaçu nectar. The results obtained, for each flow rate at the exit of the cooling tube, showed a RTD curve with a symmetrical Gaussian-like shape and an extended tail revealing that part of the flowing fluid was held back in dead regions of the equipment (Figure 3).

Therefore, $\mathrm{n}$ fractions of particles could be considered to travel through the system at different speeds. As the $\mathrm{E}(\mathrm{t})$ curves in Figure 3 showed that the major part of the dyed fluid would come out in a short period of time represented by the peak, a simplification was made. It was assumed that the particles of nectar would flow in four different fractions: fraction $z_{1}=\int_{0}^{t_{1}} E(t) d t$, with $t_{1}$ being the time corresponding to the peak; fraction $z_{2}=$ $\int_{\mathrm{t}_{1}}^{\mathrm{t}_{2}} \mathrm{E}(\mathrm{t}) \mathrm{dt}$, with $\mathrm{t}_{2}$ corresponding to the base of the peak; and the tail then divided into two fractions equally spaced in time, $z_{3}=\int_{t_{2}}^{t_{3}} E(t) d t$ and $z_{4}=\int_{t}^{t_{4}} E(t) d t$. Fraction $z_{1}$ would exit the cooling tube at time $t_{1}=\left(t_{1} / 2\right)$, fraction $z_{2}$ at time $\bar{t}_{2}=t_{1}+\left(t_{2}-t_{1}\right) / 2$, fraction $z_{3}$ at time $\bar{t}_{3}=t_{2}+\left(t_{3}\right.$ $\left.-t_{2}\right) / 2$, and finally fraction $z_{4}$ at $\bar{t}_{4}=t_{3}+\left(t_{4}-t_{3}\right) / 2$. The time-temperature histories were corrected adding $\bar{t}_{n}$ to all the time values of the original profile from the exit of the pasteurizer to the end of the system. For each original time-temperature history, four profiles were therefore obtained with a corresponding delay of $\overline{\mathrm{t}}_{1}, \overline{\mathrm{t}}_{2}, \overline{\mathrm{t}}_{3}$ and $\overline{\mathrm{t}}_{4}$. The $G$ values were corrected using the following equations:

$$
\begin{gathered}
\mathrm{G}_{\mathrm{n}}=\int_{0}^{\overline{\mathrm{t}}_{\mathrm{n}}} \exp \left\{-\frac{\mathrm{E}_{\mathrm{a}}}{\mathrm{RT} \mathrm{T}_{(\mathrm{t})}}\right\} \mathrm{dt} \\
\mathrm{G}=\sum_{\mathrm{n}=1}^{4} \mathrm{G}_{\mathrm{n}} \mathrm{z}_{\mathrm{n}}
\end{gathered}
$$

Analysis of Results. The FORTRAN program "Kinprm" was devel oped to apply the PEIE method step by step:

(1) Enter arbitrarily two activation energy values $\left(E_{a 11}\right.$ and $E_{a 12}=2 \times E_{a 11}$ ) (in this study $E_{a 11}=60 \mathrm{~kJ} / \mathrm{mol}$ ).

(2) Calculate $G$ value (eq 1 ) for each thermal profile and for each $E_{a}$ value. To integrate the equation a trapezoidal method was used.

(3) Determine the EIE $\left(T_{E}, t_{E}\right)$ for each dynamic heating pair, (eqs $4 a$ and $4 b$ ).

(4) Calculate the isothermal rate constants from EIE data and experimental thermal degradation of AA (eq 5).

(5) Calculate the new $E_{a}$ values for each thermal process pair (eq 8) (6):

$$
E_{a_{1}}=\frac{R \ln \left(\frac{k_{E_{1}}}{k_{E_{2}}}\right)}{\left(\frac{T_{E_{1}}-T_{E_{2}}}{T_{E_{1}} T_{E_{2}}}\right)} ; \quad E_{a_{2}}=2 E_{a_{1}}
$$

(6) Replace the originally selected $E_{a}$ 's with the obtained ones and repeat the whole procedure until the $E_{a}$ values match in consecutive iterations (convergence criteria, $\epsilon=0.0001$ ).

Another FORTRAN program, "Cdegrad", was also devel oped to predict extents of reaction. It estimates the $G$ values from the experimental heating profile (eq 3 ) and next calculates the AA degradation, when the kinetic parameters are known:

$$
\frac{C}{C_{0}}=e^{-k_{\text {tref }} G_{\text {Tref }}}
$$

\section{Results and Discussion}

Data from all of the 15 experiments, thermal profiles (F igure $2 \mathrm{a}-\mathrm{c}$ ) and corresponding ascor bic acid retention (Table 2) were used in the PEIE method to determine the kinetic parameters. By applying the Arrhenius law to the data obtained ( $\mathrm{K}_{\mathrm{E}}$ 's and corresponding $\mathrm{T}_{\mathrm{E}}$ 'S) an $\mathrm{E}_{\mathrm{a}}$ of $73 \pm 9 \mathrm{~kJ} / \mathrm{mol}$ and $a \mathrm{k}_{80^{\circ} \mathrm{C}}$ of $0.017 \pm 0.001 \mathrm{~min}^{-1}$ were obtained (Table 3, Figure 4). From the regression analysis performed, an $\mathrm{R}^{2}$ of 0.715 could indicate relatively poor correlation. However, the residuals analysis showed that the regression line obtained with the estimated parameters presented a good fit. Three residues, higher than 1, were considered as outliers and discarded (Figure 
Table 2. Experimental Final Retention for Ascorbic Acid (AA) in Cupuaçu Nectar for All Thermal Treatments

\begin{tabular}{|c|c|c|c|c|}
\hline run & $\begin{array}{l}\text { max temp } \\
\text { reached }\left({ }^{\circ} \mathrm{C}\right)\end{array}$ & $\begin{array}{l}\text { no. of } \\
\text { cycles }\end{array}$ & $\begin{array}{c}\text { flow rate } \\
(\mathrm{L} / \mathrm{h})\end{array}$ & $\left(\mathrm{C} / \mathrm{C}_{0}\right)_{\exp }$ \\
\hline 1 & 98 & 2 & 4.8 & 0.46 \\
\hline 2 & 98 & 1 & 3.6 & 0.72 \\
\hline 3 & 98 & 1 & 4.8 & 0.69 \\
\hline 4 & 80 & 1 & 3.0 & 0.65 \\
\hline 5 & 90 & 1 & 3.6 & 0.83 \\
\hline 6 & 90 & 3 & 8.4 & 0.45 \\
\hline 7 & 85 & 1 & 4.8 & 0.76 \\
\hline 8 & 70 & 1 & 3.0 & 0.78 \\
\hline 9 & 90 & 2 & 8.4 & 0.79 \\
\hline 10 & 80 & 3 & 8.4 & 0.56 \\
\hline 11 & 70 & 3 & 8.4 & 0.76 \\
\hline 12 & 90 & 1 & 8.4 & 0.97 \\
\hline 13 & 70 & 2 & 8.4 & 0.9 \\
\hline 14 & 60 & 3 & 8.4 & 0.94 \\
\hline 15 & 80 & 2 & 8.4 & 0.79 \\
\hline
\end{tabular}

Table 3. Kinetic Parameters of Thermal Degradation of Ascorbic Acid (AA) in Cupuacu Nectar Using the PEIE Method (18 ${ }^{\circ}$ Brix, pH 3.2) (16)

\begin{tabular}{lll}
\hline & \multicolumn{2}{c}{ regression analysis results } \\
\cline { 2 - 3 } & \multicolumn{1}{c}{$\begin{array}{c}\text { without } \mathrm{RTD} \\
\text { correction }\end{array}$} & \multicolumn{1}{c}{$\begin{array}{c}\text { after } \mathrm{RTD} \\
\text { correction }\end{array}$} \\
\hline $\mathrm{E}_{\mathrm{a}}$ & $73 \pm 9 \mathrm{~kJ} / \mathrm{mol}$ & $74 \pm 10 \mathrm{~kJ} / \mathrm{mol}$ \\
$\mathrm{K}_{80^{\circ} \mathrm{C}}$ & $0.017 \pm 0.001 \mathrm{~min}^{-1}$ & $0.013 \pm 0.001 \mathrm{~min}^{-1}$ \\
$\mathrm{R}^{2}$ & 0.715 & 0.716 \\
no. of observations & 102 & 90
\end{tabular}

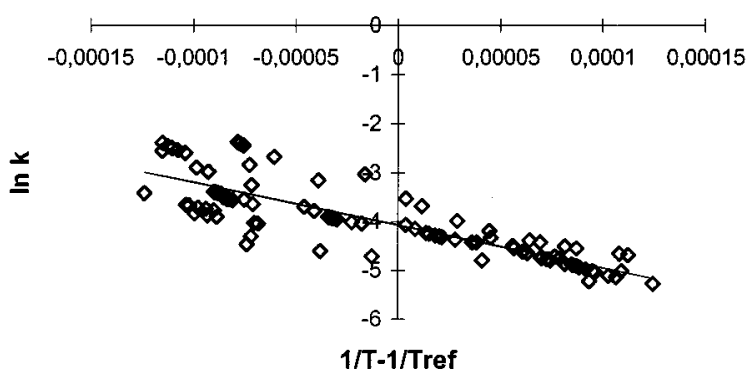

Figure 4. PEIE Arrhenius plot obtained using all 15 thermal treatments, after 12 iterations.

5). Correction of the $\mathrm{G}$ values, taking into account the residence time distribution (eqs 6 and 7), had just a slight effect in approximating the estimated values to the experimental ones and had the disadvantage of losing combinations (Table 3, Figure 6).

When applying the PEIE method, as 15 experiments were used, 105 combinations were expected to be obtained, but some combinations were lost as a result of several reasons (6): (1) Some combinations lead to negative values of $E_{a}$, when in a combination $T_{E_{1}}<T_{E_{2}}$ and $k_{E_{1}}>k_{E_{2}}$ or vice versa. 2) Some combinations lead to very close values of $T_{E}$ or $t_{E}$, and the $E_{a}$ values obtained were too high or too low when compared to the average values. Therefore, two conditions were imposed in the program Kinprm:

$$
\left(T_{E_{1}}-T_{E_{2}}\right) /\left(k_{E_{1}}-k_{E_{2}}\right)>0 \text { and }\left|T_{E_{1}}-T_{E_{2}}\right|>3
$$

One way of avoiding more losses of data points was to sort the thermal processes in decreasing order of $\mathrm{G}$. This procedure would work in perfection if the experimental retention would increase with $\mathrm{G}$ decreasing; however, some experimental results were out of order because of experimental error.

Even when the PEIE was tested using retention values obtained from eq 9 , predicted with the kinetic parameters

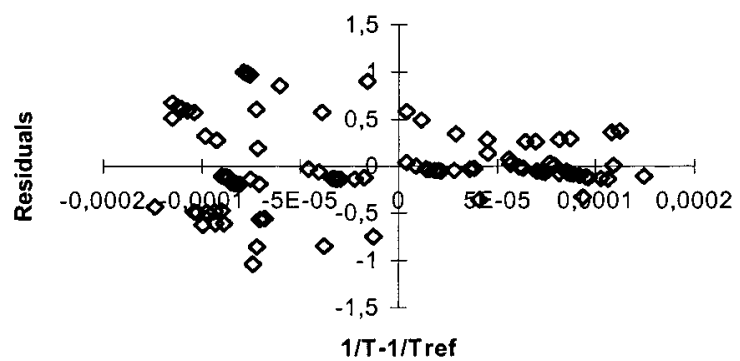

Figure 5. Residual analysis of the regression of In $\mathrm{k}$ vs $1 / T_{\mathrm{E}}$ (relative to Figure 4).

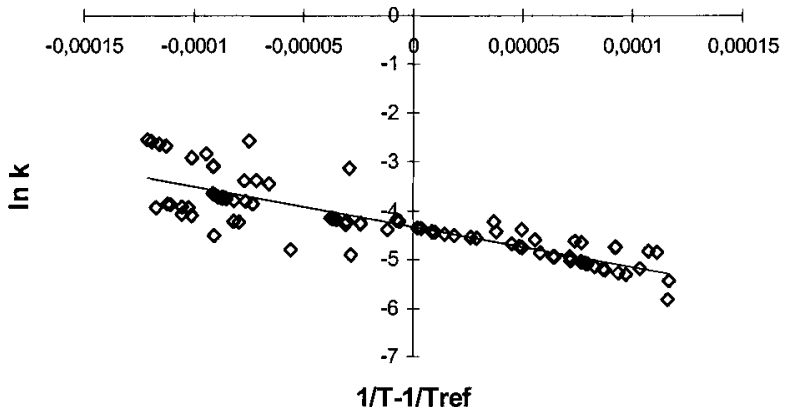

Figure 6. PEIE Arrhenius plot obtained using all 15 thermal treatments, after 12 iterations and considering the residence time distribution $\mathrm{E}(\mathrm{t})$.

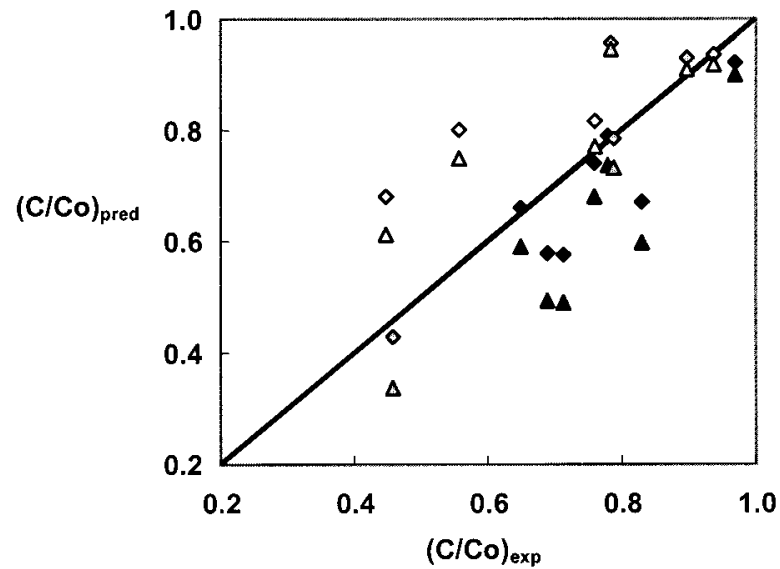

Figure 7. Scatter diagram of predicted values of $C / C_{0}$ vs experimental values $C / C_{0}$ for all 15 dynamic experiments. Predicted ascorbic acid degradation values obtained with the kinetic parameters estimated by the PEIE method are represented by diamonds (black for one cycle, gray for two cycles, and white for three cycles). Predicted values obtained with the kinetic parameters estimated from the isothermal experiments (16) are represented by triangles (black for one cycle, gray for two cycles, and white for three cycles).

obtained from the isothermal experiments (Table 1), 23 combinations of thermal treatments were not valid as a result of very close thermal treatments. From Figure 7 , it can be observed that the predicted values of extent of reaction using either the results from the isothermal method (Table 1) or the PEIE method (Table 3) present a good fit to the experimental values. However, the values predicted by the isothermal method are always slightly lower. This trend is more noticed for higher $G$ values. For the cycled heating experiments, it was observed that for temperatures above $70^{\circ} \mathrm{C}$ a second pass through the equipment leads to more degradation than what should occur if an equivalent one-cycle thermal treatment had been applied. A third cycle enhances this behavior even more. This different behavior (between single and cycled heat treatments) suggests that when the product is 
thermally processed only once, either free radicals are formed or chemical bonds become weaker. However, we think that the major cause was the increase in dissolved oxygen in the nectar, allowed by this process and leading to more degradation, although it has to be taken into account that the process of oxidation will be even more enhanced during shelf life. Marshal et al. in 1985 (19) alerted to the fact that aseptic processing (as an alternative to hot-fill and hold processing) would only impart a higher quality to fruit juices that were consumed in a short period of time after thermal processing. If stored for long periods of time, the higher oxygen content due to the kind of processing, would cause a decrease in quality through the appearance of nonenzymatic browning, unpleasant flavors and higher degradation of ascorbic acid.

One of the advantages of the PEIE method is to determine kinetic data in an easy and faster way, saving laboratory time and reagents. The need of specific equipment for the purpose is evident, to have enough flexibility to produce sufficiently different thermal processes. A much longer holding tube with thermocouples inserted throughout the length of the tube and the possibility of having a wider range of flow rates would avoid losing so many data points, and fewer experiments would also be necessary, leading to a much less time-consuming method. The pasteurizer also has to take into account the rheol ogy of the fluid.

\section{Conclusions}

Correction of the $\mathrm{G}$ values, considering the residence time distribution, did not improve the PEIE method results. It had just a slight effect in approximating the estimated values to the experimental ones and had the disadvantage of losing combinations.

Pulsed heating exposures produced greater difference between the experimental values and the estimated values (\% error) than for the single heating set, mainly for the higher temperatures, and this was probably due to the experimental procedure.

The PEIE method predicts degradation values sometimes lower than the values obtained experimentally, underestimating the thermal treatment, which is in favor of safety. The kinetic parameters estimated by the PEIE method (Table 3 ) were very close to the values obtained previously by the isothermal method (Table 1).

Although the PEIE method is only applicable for firstorder reactions at this time, it is easier and faster to determine kinetic data, saving laboratory time and equipment.

\section{Notation}

\begin{tabular}{|c|c|}
\hline$\epsilon$ & convergence criteria \\
\hline AA & ascorbic acid \\
\hline C & concentration \\
\hline$E(t)$ & resident time distribution function \\
\hline $\mathrm{E}_{\mathrm{a}}$ & activation energy (kJ /mol) \\
\hline $\mathrm{F}_{0}$ & $\begin{array}{l}\text { sterilizing value (equivalent processing time at } \\
121.1{ }^{\circ} \mathrm{C} \text {, with a } \mathrm{z} \text { value of } 10^{\circ} \mathrm{C} \text { ) }\end{array}$ \\
\hline G & thermal reduction relationship \\
\hline k & rate of the reaction $\left(\mathrm{min}^{-1}\right)$ \\
\hline PEIE & paired equivalent isothermal exposures \\
\hline $\mathrm{R}$ & universal gas constant $(8.314 \mathrm{~kJ} / \mathrm{mol} \mathrm{K})$ \\
\hline RTD & resident time distribution \\
\hline $\mathrm{t}$ & time (min) \\
\hline$\overline{\mathrm{t}}$ & average time (min) \\
\hline $\mathrm{T}$ & absolute temperature $(\mathrm{K})$ \\
\hline
\end{tabular}

$\mathrm{T}(\mathrm{t}) \quad$ time-temperature history $(\mathrm{K})$

\section{Subscripts}

$\begin{array}{ll}\text { exp } & \text { experimental } \\ \text { pred } & \text { predicted } \\ \text { ref } & \text { at the reference temperature } \\ \mathrm{t} & \text { total } \\ \infty & \text { final value; at equilibrium } \\ \mathrm{E} & \text { equivalent } \\ 0 & \text { initial value, at time equal to zero }\end{array}$

\section{Acknowledgment}

M. C. Vieira acknowledges a PRODEP Ph.D. grant to the University of Algarve and Ministério da Educação of Portugal. This work was supported in part by the European Union, contract STD no. ERB-TS3-CT94-300, project "Etude Pluridisciplinaire de Transformations de Fruits Amazoniens en Vue de Leur Valorisation Commerciale par les Organisations Paysannes Existantes".

\section{References and Notes}

(1) Holdsworth, S. D. Sterilisation of Food Products and Associated Physico Chemical Changes. In Aseptic Processing and Packaging of Food Products; Chapman and Hall: London, 1992; Chapter 3, pp 27-73.

(2) Cohen, F.; Birk, Y.; Mannheim, C. H.; Saguy, I. S. Kinetic Parameter Estimation for Quality Change During Continuous Thermal Processing of Grapefruit J uice. J . F ood Sci. 1994, 59(1), 155-158.

(3) Silva, C. L. M. Optimization of Sterilized Conduction Heated Foods: A Generalized Approach. Ph.D. Thesis, E scola Supe rior de Biotecnologia, Universidade Católica Portuguesa, Porto, Portugal, 1993.

(4) Nasri, H.; Simpson, R.; Bouzas, J .; Torres, J . A. An UnsteadyState Method to Determine Kinetic Parameters for Heat Inactivation of Quality Factors: Conduction-Heated Foods. J. Food Eng. 1993, 19, 291-301.

(5) Swartzel, K. R. A Continuous Flow Procedure for Reaction Kinetic Data Generation. J . Food Sci. 1984, 49(3), 803-806.

(6) Welt, B. A.; Teixeira, A. A.; Balaban, M. O.; Semerage, G. H.; Sage D. S. Iterative Method for Kinetic Parameter Estimation from Dynamic Thermal Treatments. J . Food Sci. 1997a, 62(1), 8-14.

(7) Nunes, R. V.; Swartzel, K. R. Modeling Thermal Processes Using the Equivalent Point Method. J . Food Eng. 1990, 11, 103-107.

(8) Sadeghi, F.; Hamid-Samimi, M. H.; Swartzel, K. R. MicroComputer Program for Determining the Unique TimeTemperature Associated with the Equivalent Point Method of Thermal Evaluation. J . Food Proc. Preserv. 1986, 10, 331335.

(9) Nunes, R. V.; Swartzel, K. R.; Ollis, D. F. Thermal Evaluation of Food Processes: The Role Of A Reference Temperature. J . Food Eng. 1993, 20(1), 1-15.

(10) Miles, J. J .; Swartzel, K. R. Evaluation of Continuous Thermal Processes U sing Thermocouple Data and Calibration Reactions. J . Food Proc. Eng. 1995, 18, 99-113.

(11) Maesmans, G.; Hendrickx, M.; De Cordt, S.; Van Loey, A.; Noronha, J.; Tobback, P. Combined Use of the Equivalent Point Method and a Multicomponent Time-Temperature Integrator in Thermal Process Evaluation: Influence of Kinetic Characteristics and Reference Temperature. Food Control 1994, 5(4), 249-256.

(12) Maesmans, G.; Hendrickx, M.; De Cordt, S.; Tobback, P. Theoretical Consideration of the General Validity of the Equivalent Point Method in Thermal Process Evaluation. J . Food Eng. 1995, 24(2), 225-248.

(13) Wescott, G. G.; Fairchild, T. M.; F oegeding, P. M. Bacillus cereus and Bacillus stearothermophilus Spores I nactivation in Batch and Continuous Flow Systems. J . Food Sci. 1995, 60(3), 446-450. 
(14) Welt, B. A.; Teixeira, A. A.; Balaban, M. O.; Semerage, G. H.; Hintinlang, D. E.; Smittle, B. J. Kinetic Parameter Estimation in Conduction Heating Foods Subjected to Dynamic Thermal Treatments. J . Food Sci. 1997b 62(3), 529$534,538$.

(15) Kyereme, M.; Swartzel, K. R.; Farkas, B. E. New Line Intersection Procedure for the Equivalent Point Method of Thermal Evaluation. J . Food Sci. 1999, 64(4), 565-570.

(16) Vieira, M. C.; Teixeira, A. A.; Silva, C. L. M. Mathematical Modeling of the Thermal Degradation Kinetics of Total Vitamin C in Cupuaçu (Theobroma grandiflorum) Nectar. J . Food Eng. 2000, 43, 1-7.

(17) Lenz, M. K.; Lund, D. B. Experimental Procedures for Determining Destruction Kinetics of F ood Components. F ood Technol. 1980, 51-55.
(18) Fellows, P. Pasteurisation. In Food Processing and Technology; Ellis Horwood/NCH Publishers: New York, 1998; Chapter 10, pp 210-219.

(19) Marshall, M.; Nagy, S.; Russell, R. Factors impacting on the quality of stored citrus fruit beverages. In Developments in Food Science 12, The Shelf Life of Foods and Beverages, Proceedings of the 4th International Flavor Conference, Rhodes, Greece, 23-26 J uly 1985. Charalambous, G., Ed.; Elsevier Science Publishers: Amsterdam, 1985; pp 237-254.

Accepted for publication September 27, 2000.

BP000132W 